Carla Liliane Waldow Esquive $\left.\right|^{1,3}$

Tatyana Scheila Friedrich ${ }^{2,3}$

\title{
A GÊNESE DA GLOBALIZAÇÃO DA DOENÇA E A INTERNACIONALIZAÇÃO DO DIREITO À SAÚDE ${ }^{1}$
}

The genesis of the globalization of disease and the consequent globalization of right to health

${ }^{1}$ Universidade Estadual do Oeste do Paraná. Marechal Cândido Rondon/PR, Brasil. ${ }^{2}$ Universidade Federal do Paraná. Curitiba/PR, Brasil.

${ }^{3}$ Núcleo de Pesquisa em Direito Público do Mercosul da Universidade Federal do Paraná. Curitiba/PR, Brasil.

Correspondência: Carla Liliane Waldow Esquivel.E-mail: carlawaldow@hotmail.com.

Recebido em: 26/02/2014. Revisado em: 24/09/2014. Aprovado em: 20/10/2014.

\footnotetext{
${ }^{1}$ Artigo escrito no âmbito do Doutorado Interinstitucional, Universidade Federal do Paraná/Universidade Estadual do Oeste do Paraná. Apoio: Itaipu Binacional e Fundação Parque Tecnológico Itaipu-Brasil pelo Convênio n. 4500021500 .
} 


\section{RESUMO}

A internacionalização da doença ocorre com o trânsito de pessoas e de bens através das fronteiras, devido sobretudo, entre outras circunstâncias, ao advento da globalização econômica. Em decorrência dessa internacionalização dos problemas sanitários, surge a necessidade da adoção de medidas de caráter transnacional para sua prevenção e contenção. Nesse ambiente, advêm as conferências sanitárias internacionais, importantes organismos internacionais e regionais e, principalmente, documentos normativos que servem como mera orientação aos governos locais ou como normas vinculantes. É nesse contexto que aparece e se consolida o direito à saúde como bem-estar integral dos indivíduos, competindo aos Estados sua concretização.

\section{Palavras-chave}

Direito à Saúde; Doença; Internacionalização; Saúde.

\section{ABSTRACT}

The international spread of diseases occurs when people and goods cross borders. This spread is most commonly due to the advent of economic globalization. Because of the globalization of human health problems, there is now a need for international measures to be adopted to prevent and contain disease. This situation has given rise to international conferences on health, important regional and international organizations, and, most significantly, legislative documents that offer mere guidance to local governments or list binding norms. It is in light of this situation that the right to health care has emerged and been established as being integral to a population's well-being, and as a concept that governments are competing to implement.

\section{Keywords}

Disease; Globalization; Health; Right to Health. 


\section{Introdução}

O presente trabalho, de viés histórico, tem por objetivo identificar a gênese da internacionalização das doenças e, como consequência, das medidas sanitárias que foram gradativamente implementadas, dando lugar ao reconhecimento da saúde como um direito humano fundamental. Tal reconhecimento ocorreu em importantes documentos legislativos, ultrapassando os limites internos dos Estados.

Importa, preliminarmente, esclarecer que o termo "saúde" deve ser compreendido para além da explicação médica, alcançando outros saberes, tais como o direito. Além de uma concepção multifacetada, o tema saúde gera inquietação e influencia diferentes segmentos sociais, como a religião, a educação e, em especial, a política e a economia. Nessa dimensão de múltiplos aspectos, a saúde deverá ser entendida, antes de tudo, como um estado completo de bem-estar físico, mental e social, embora, em uma investigação de suas origens, verifique-se uma concepção basicamente relacionada à ausência de doença. Saúde pública, por sua vez, deve ser entendida ,como a saúde de toda a população, de nacionais ou não nacionais que compõem o Estado e que se relacionam com os demais. Sob essa perspectiva, converte-se em um bem jurídico supraindividual, cuja inquietação transcende a esfera do indivíduo e o âmbito nacional, permitindo um olhar para o conjunto e para a consecução de medidas multilaterais. O direito à saúde, por outro lado, é o resultado do reconhecimento legal, seja em nível local ou internacional, do direito ao cuidado e à posse do melhor estado de saúde por meio do acesso universal e igualitário às ações públicas direcionadas a sua implementação ${ }^{2}$. No tocante à globalização, deve ser compreendida como o intercâmbio transnacional em que uma determinada localidade amplia seu âmbito de relações para todo o globo ${ }^{3}$, numa interconexão entre os sujeitos e os valores que permeiam tais relações, como aqueles que se referem à concepção de bem-estar e de direitos que as pessoas possuem.

A fim de realizar este trabalho, considerando-se os aspectos acima tracejados, buscar-se-á fazer um levantamento histórico do reconhecimento da doença e da necessidade de cuidados para a recuperação, promoção e proteção da saúde e, depois, a partir da ideia de contágio, avançar na análise dos esforços coletivos, inclusive internacionais, para a contenção e prevenção da doença.

Para tanto, recorrer-se-á ao método de abordagem histórica e ao método dialético, pelo qual, a partir de um diálogo entre afirmações e oposições, infere-se uma síntese. Serão analisadas a doutrina e legislações internacionais relacionadas

\footnotetext{
${ }^{2}$ DALLARI, Sueli Gandolfi. Direito sanitário. In: ARANHA, Márcio lorio (Coord). Direito sanitário e saúde pública. Coletânea de Textos. Ministério da Saúde. Secretaria de Gestão do Trabalho e da Educação na Família. Departamento de Gestão da Educação da Saúde. Brasília: Ministério da Saúde, 2003. p. 46

${ }^{3}$ SANTOS, Boaventura de Sousa. La globalización del derecho: los nuevos caminhos de la regulación y la emancipación. Bogotá: ILSA, 1998. p. 37-39, 56.
} 
ao tema, a fim de se direcionarem futuras conclusões a respeito da formatação legal do direito à saúde desde suas pioneiras manifestações até a perspectiva de proteção internacional multilateral.

\section{0 devir histórico da internacionalização do direito à saúde}

É possível dizer que, ao contrário do que se poderia imaginar, ainda que com contornos um pouco diversos, a ideia de saúde ou de cuidados sanitários, inclusive em âmbito internacional, já se fazia presente no primeiro estágio da civilização.

Fazendo-se uma digressão histórica, constata-se a disseminação de doenças oriundas do próprio nomadismo primitivo e a adoção de medidas higiênicas no intuito de preservar a própria vida ${ }^{4}$. George Rosen relata que, por volta de dois mil anos antes da era cristã, os quéchuas, exímios engenheiros sanitários, ergueram cidades drenadas e com suprimento de água, garantindo um terreno seguro para a saúde da comunidade. Tinham consciência dos diversos elementos presentes no ambiente que poderiam repercutir sobre a saúde. $\mathrm{O}$ autor também faz menção a estudos de paleopatologia que datam do ano 1.000 a.C. e que mostram a antiguidade de doenças como varíola, esquistossomose, tuberculose e poliomielite, entre outras infecções, epidemias, distúrbios de desenvolvimento e de metabolismo, além de traumatismos e tumores. No mesmo período - ou seja, por volta de 500 a 1.000 a.C. - as doenças eram geralmente enfrentadas com rituais pagãos ou religiosos ${ }^{5}$. Nesse sentido e a partir da era cristã, as atividades sanitárias eram atribuídas à Igreja, vinculando-se saúde e doença à ideia de graça divina e castigo. Somente depois foi retomado o caráter científico instaurado pelos gregos, que defendiam a concepção de equilíbrio entre o homem e a natureza, para a investigação de determinadas moléstias $\mathrm{O}$ conceito de doença, nesse primeiro momento, dizia respeito tanto aos males físicos quanto espirituais, e a definição de saúde passava a ser delimitada por seu oposto (doença) - com a necessidade de intervenção curativa e, como consequência, a preservação da espécie, em que os fatores ambientais tiveram reconhecida importância ${ }^{6}$.

Em relação ao Medievo, particularmente no século XIV na Alemanha e na Itália, problemas sanitários da vida urbana - especialmente os que se referiam ao crescimento das cidades, à sanidade da água, à comercialização de alimentos e à proliferação de doenças - originaram as primeiras regulamentações a respeito da saúde coletiva. No entanto, o que mais marcou o período foi o aparecimento de inúmeras epidemias que se espalharam pela Europa, destacadamente em razão do trânsito de pessoas e de mercadorias oriundas de diversos lugares e por diferentes

${ }^{4}$ REZENDE, Ana Lúcia Magela de. Saúde: dialética do pensar e do fazer. 2. ed. São Paulo: Cortez, 1989. p. 14-15. ${ }^{5}$ ROSEN, George. Uma história da saúde pública. 2. ed. São Paulo: Hucitec, 1994. p. 32.

${ }^{6}$ DALLARI, Sueli Gandolfi. Direito sanitário, cit., p. 39; SCHWARTZ, Germano. Direito à saúde: efetivação em uma perspectiva sistêmica. Porto Alegre: Livraria do Advogado, 2001. p. 28. 
razões através das fronteiras. Em consequência disso, foram adotadas medidas de caráter sanitário preventivo, como o isolamento e a quarentena ${ }^{7}$. De acordo com Sueli Gandolfi Dalari, a reação coletiva à epidemia é a imagem mais marcante do período, aparecendo os primeiros contornos da noção de saúde-prevenção, cuja expressão mais evidente era o afastamento dos impuros, não obstante o manifesto objetivo de impedir a desordem econômica ${ }^{8}$.

Verifica-se que a ideia de contágio e a necessidade de adoção de medidas sanitárias preventivas de caráter transnacional eram claras na Idade Média, dando início ao que Michel Foucault denominou vigilância epidemiológica, sobretudo nos portos, locais de circulação de pessoas e de bens. Tais medidas sanitárias, presentes nesse período, estenderam-se por todo o século XVII até a segunda metade do século XVIII, porém modificando seu significado para alcançar uma forma de medicina de exclusão e de assistência à saúde por meio das fundações de caridade que prestavam auxílio material, inclusive com o fornecimento de medicamentos. A concepção de saúde não deixou de privilegiar o aspecto preventivo, levando em consideração a noção de perigo social elaborada à época9

No período que se estendeu da segunda metade do século XVIII até o início do XIX, passou-se à preocupação com a organização do saber científico global em relação a questões afetas à saúde coletiva. Foi nesse contexto que o Estado desempenhou diferentes papéis, destacadamente a distribuição gratuita de produtos médicos, como ocorreu na França de Luis XIV a Luis XVI. Igualmente nesse período, houve a expansão da doença, que se deveu ao incremento da tecnologia, à melhoria das condições de comunicação entre os Estados e ao aprofundamento das inquietações relacionadas aos prejuízos que as doenças poderiam causar à produção e à economia. Portanto, a doença era compreendida como transtorno econômico, enquanto a saúde fundava-se na ideia curativa e no sentido de ausência de enfermidade. Tal concepção foi particularmente enfatizada no final do século XIX e na primeira metade do século XX, com a descoberta dos germes causadores de doenças e com o desenvolvimento de medicamentos específicos, drogas aperfeiçoadas para o emprego mais adequado e tecnologia farmacêutica passível de produção em grande escala. Apesar do indubitável viés economicista do conceito (saúde-doença), esse tempo foi marcado pela atenção científica à saúde e pelo surgimento dos primeiros movimentos internacionais relacionados à saúde comunitária. O Estado, então, passou

\footnotetext{
${ }^{7}$ Entre as razões desses deslocamentos podem-se destacar os conflitos bélicos e as transações econômicas transfronteiriças, que disseminaram doenças como a lepra e a varíola. (BATISTA, Vanessa Oliveira. $A$ proteção internacional do direito à saúde. p. 23. Disponível em: <www.estig.ipbeja.pt/ ac_direito/Vanessa. doc>. Acesso em: 22 jul. 2013; ROSEN, George, op. cit., p. 55-63; 78; 92-98; FOUCAULT, Michel. Microfísica do poder. 5. ed. Rio de Janeiro: Edições Graal, 1985. p. 82-88).

${ }^{8}$ DALLARI, Sueli Gandolfi. Direito sanitário, cit., p. 39; FOUCAULT, Michel. op. cit., p. 103-104.

${ }^{9}$ Id. Direito sanitário, cit., p. 40.
} 
a se relacionar com os demais Estados visando a implementar medidas conjuntas para soluções satisfatórias aos fins comuns ${ }^{10}$.

Deve-se observar que o papel do Estado não se limitou à função assistencial nesse ínterim. As medidas de caráter sanitário de contenção das enfermidades passaram a conviver com documentos que reconheciam os direitos mais fundamentais do homem - ganhando terreno, nesse devir histórico, o direito à saúde. Registre-se que, apesar do caráter conveniente e pretensioso dos primeiros documentos legislativos que albergaram os direitos fundamentais do homem, eles representaram o início da reivindicação universal por meios e condições de vida mais dignos ${ }^{11}$.

Foi assim que, no âmbito do aparecimento de grandes epidemias - e, portanto, de riscos à saúde -, da indispensabilidade de sua contenção e prevenção através de mecanismos de segurança e da constatação de que as enfermidades ultrapassam as fronteiras geográficas, houve a necessidade de buscar soluções e cooperação em nível internacional no campo da saúde pública. E os primeiros passos para o controle multilateral das epidemias através da legislação sanitária internacional se deu no início do século XIX. Conta George Rosen que Mehemet Ali, soberano no Egito, criou um conselho sanitário composto por representantes de vários países da Europa no intuito de protegê-los, colocando em pauta problemas relacionados à quarentena e à higiene internacional. Referido conselho, chefiado por uma Comissão de Saúde Consular, vigorou de 1833 a 1839, quando foi dissolvido pelo mesmo soberano. O mesmo autor indica que a cooperação internacional também havia sido iniciada em outros locais e sob circunstâncias diferentes. Assim, em 1839, em um encontro em Constantinopla, houve uma reunião entre o Comitê de Saúde da Sublime Porta ${ }^{12}$ e os representantes das forças estrangeiras para cuidar da quarentena e colocar em ordem problemas relativos a sua interferência no comércio. Na França, em 1834 houve a primeira proposta de uma Conferência Sanitária Internacional, reiterada pelo governo britânico em 1843. No entanto, somente em 1851 foi realizada, em Paris, a primeira Conferência Sanitária Internacional, com a presença da Áustria-Hungria,

\footnotetext{
${ }^{10}$ SCHWARTZ, Germano. op. cit., p. 33-35; DALLARI, Sueli Gandolfi. Poderes republicanos e a defesa do direito à saúde: evolução da proteção do direito à saúde nas Constituições do Brasil. In: BRASIL. Ministério da Saúde. Direito Sanitário em Perspectiva. Brasília: Fundação Oswaldo Cruz, 2013. v. 2, p. 21-22.

${ }^{11}$ Antes mesmo da Declaração de Direitos de 1789, outros importantes documentos surgiram, permeados de boas e não tão boas intenções. Nesse sentido, é de se lembrar da Magna Carta Inglesa de 1215 que, embora tenha sido elaborada para proteger os privilégios dos barões e os direitos dos homens livres, tornou-se um símbolo das liberdades públicas e fonte dos fundamentos da ordem jurídica democrática do povo inglês. Importante também foi a Petition of Rights, de 1628, que nada mais fez que rogar pela observância de direitos e liberdades já consagrados na Magna Carta. De importância ímpar foi a Declaração de Direitos (Bill of Rights, de 1688) para reiterar a declaração de direitos e fazer surgir a monarquia constitucional, submetida à soberania popular. Ademais, a Declaração de Direitos do Bom Povo da Virgínia, de 1776, representou a primeira declaração de direitos fundamentais, consubstanciando a base dos direitos do homem e de um governo democrático (SILVA, José Afonso da. Curso de direito constitucional positivo. 33. ed. rev. e atual. São Paulo: Saraiva, 2010. p. 152-154).

${ }^{12}$ Designação conferida ao antigo governo turco.
} 
das duas Sicílias, da Espanha, dos Estados Papais ${ }^{13}$, da Grã-Bretanha, da Grécia, de Portugal, da França, da Rússia, da Sardenha, da Toscana e da Turquia. A partir dessa convenção, surgiram diversas normas que representaram a tentativa de criar um código sanitário internacional. Posteriormente, ocorreram outras conferências internacionais de saúde em Paris (1859), Constantinopla (1866), Viena (1874) e Washington (1881). Estava ali o germe do direito sanitário internacional ${ }^{14}$.

Paralelamente, em 1863, o Comitê Internacional da Cruz Vermelha ${ }^{15}$ surgiu com o objetivo de assegurar a proteção e a assistência às vítimas de lutas e conflitos armados. À época de sua criação, pretendia-se examinar formas de eliminar a insuficiência do serviço sanitário nos exércitos de campanha, além de aplicar o direito internacional humanitário e conscientizar os governos e portadores de armas. Em decorrência desses primeiros esforços, em 1864 o Comitê convenceu os governos a adotarem a primeira Convenção de Genebra, que obrigava os exércitos a cuidarem dos soldados feridos, independentemente do lado a que pertencessem. A partir de então despontaram várias organizações para socorro de feridos em conflitos armados ${ }^{16}$.

Além do surgimento do aludido comitê e das primeiras convenções sanitárias internacionais para a contenção de epidemias como a cólera e a praga, surgiu também o Comitê Sanitário Internacional (1902) ${ }^{17}$. Em 1907, foi assinado um acordo em Roma instituindo o Escritório Internacional de Higiene Pública, a primeira organização internacional de saúde de âmbito mundial. Em 1923, fundou-se a Organização de Saúde da Liga das Nações, cuja preocupação ultrapassava a esfera da quarentena para o controle de doenças contagiosas que exigiam a ação mundial - como ocorreu na Primeira Guerra, quando a expansão da malária exigiu sua intervenção. Além dos programas de ação de cunho sanitário para a Europa, a Ásia e as Américas, a organização foi essencial para criar a noção da necessidade de cooperação internacional na área da saúde ${ }^{18}$. De importância fundamental, nesse contexto, foi a criação do Primeiro Código Sanitário Internacional, que emergiu a partir da VII Conferência Sanitária Pan-Americana de Havana, em 1924. A partir de então, despontaram os acordos internacionais e as convenções que passaram a regular determinadas situações, modificados ou substituídos posteriormente - como

\footnotetext{
${ }^{13} \mathrm{~A}$ denominação refere-se aos Estados pertencentes à Igreja e, portanto sob autoridade civil dos Papas, formados pelo conjunto de estados independentes, localizados no centro da península Itálica até aproximadamente 1870.

${ }^{14}$ ROSEN, George, op. cit., p. 212-213; VENTURA, Deisy de Freitas Lima. Direito internacional sanitário. In: ARANHA, Márcio lorio (Coord.). Direito sanitário e saúde pública. Coletânea de Textos. Ministério da Saúde. Secretaria de Gestão do Trabalho e da Educação na Família. Departamento de Gestão da Educação da Saúde. Brasília: Ministério da Saúde, 2003. p. 249.

${ }^{15}$ COMITÊ Internacional da Cruz Vermelha. Disponível em: <http://www.icrc.org/por/who-we-are/history/ overview-section-history-icrc.htm>. Acesso em: 04 maio 2013.

${ }^{16}$ BATISTA, Vanessa Oliveira, op. cit., p. 16.

${ }^{17}$ No mesmo ano (1902) foi criado o Escritório Pan-Americano de Saúde, considerado a mais antiga das organizações internacionais de saúde.

${ }^{18}$ ROSEN, George, op. cit., p. 212-213; 343-344.
} 
o Acordo Internacional para Dispensa de Atestado de Saúde (1934), a Convenção Sanitária Internacional e a Convenção Sanitária Internacional para a Navegação Aérea (1933 a 1944) ${ }^{19}$. Os documentos citados têm como foco a sanidade de pessoas e de bens que ultrapassam o circuito transfronteiriço através de portos e aeroportos e quaisquer outros pontos de entrada e de saída dos países ${ }^{20}$.

Sucedendo a Liga das Nações, foi constituída a Organização das Nações Unidas (ONU), especialmente para manter a paz, defender os direitos humanos e as liberdades fundamentais e promover o desenvolvimento dos Estados ${ }^{21}$. Segundo André de Carvalho Ramos, a Carta de São Francisco (o tratado internacional que criou a ONU) foi o marco do reconhecimento da vontade da comunidade internacional de promover os direitos humanos e estabelecer mecanismos de garantia e proteção de tais direitos com a necessária intervenção do Estado, em que pese o reconhecimento de direitos específicos no momento anterior ${ }^{22}$. Nesse sentido, a Carta Constitutiva das Nações Unidas, elaborada em junho de 1945, não estabeleceu expressa proteção aos direitos do homem, como, por exemplo, o direito à saúde. No entanto, proclamou a necessidade de "desenvolver e encorajar o respeito aos direitos do homem e às liberdades fundamentais de todos", sem distinção, determinando à Assembleia Geral e ao Conselho Econômico e Social, entre outras obrigações, a elevação dos níveis de vida ${ }^{23}$. Inegavelmente amparou, ainda que de forma indireta, o direito à saúde no âmbito dos Estados. Ficou clara, segundo Fabiana de Oliveira Godinho, a internacionalização dos direitos humanos. E foi através da Carta das Nações Unidas que foram estabelecidos princípios fundamentais de proteção aos direitos, posteriormente codificados e concretizados por outros documentos de caráter internacional ${ }^{24}$.

Ainda no âmbito da Organização das Nações Unidas, foi criada em 1946 a Organização Mundial da Saúde (OMS) - cuja existência oficial iniciou-se em 1948, com a ratificação de sua constituição por 26 países. De acordo com Jorge Mascarenhas Lasmar e Guilherme S. Paixão e Casarões, trata-se de uma das maiores agências especializadas da família da $\mathrm{ONU}^{25}$. Tem como função precípua coordenar os esfor-

\footnotetext{
${ }^{19}$ BATISTA, Vanessa Oliveira, op. cit., p. 24; GOMES, Carolina B.; CASTRO, Larissa de P. Gonzaga e. O novo Regulamento Sanitário Internacional. Revista de Direito Sanitário, Sâo Paulo, v. 13, n. 2, p. 139-140, jul./out. 2012; FERREIRA, Fátima de Paula; CASTRO, Larissa de Paula Gonzaga. O direito à saúde e a globalização. Revista Anhanguera, v. 11, n. 01, jan./dez. 2010, p. 67-71. Disponível em: <http://www.anhanguera.edu. br/home/index.php?option=com_docman\&ltemid=373>. Acesso em: 10 jul. 2013.

${ }^{20}$ MÍNGUEZ GONZALO, Miguel. El nuevo reglamento sanitário internacional. Revista Española de Salud Pública, Madrid, n. 03, p. 240, maio/jun. 2007. Disponível em: <http://scielo.isciii.es/pdf/resp/v81n3/editorial. pdf>. Acesso em: 01 ago. 2013.

${ }^{21}$ PEREIRA, Bruno Yepes. Curso de direito internacional público. 2. ed. São Paulo: Saraiva, 2007. p. 131.

${ }^{22}$ RAMOS, André de Carvalho. Teoria geral dos direitos humanos na ordem internacional. São Paulo: Renovar, 2005. p. 50-51.

${ }^{23} \mathrm{GODINHO}$, Fabiana de Oliveira. A proteção internacional dos direitos humanos. Belo Horizonte: Del Rey, 2006. p. 9-10.

${ }^{24}$ Id. Ibid., p. 9-10.

${ }^{25}$ LASMAR, Jorge Mascarenhas; CASARÕES, Guilherme Stolle Paixão e. A Organização das Nações Unidas. Belo Horizonte: Del Rey, 2006. p. 114.
} 
ços e programas internacionais destinados a auxiliar a comunidade internacional a alcançar o mais alto nível possível de saúde. E é a partir da Constituição da OMS que o direito à saúde começa a ser delineado como um direito fundamental de todo homem "gozar do grau máximo de saúde"26. Abandona-se, dessa maneira, a ideia primária de saúde ligada ao funcionamento do organismo, passando a abarcar outros aspectos que inevitavelmente estão associados à qualidade de vida. Por conseguinte, sob essa nova perspectiva, renuncia-se igualmente à ideia de saúde ligada aos processos curativos para alcançar a prevenção de doenças através das condições essenciais a uma saúde integral. Nesse sentido, a partir da definição exarada pela OMS, a saúde pode ser compreendida como um estágio de bem-estar e de adaptação física, mental e social ao meio, enquanto a doença pode ser concebida como desadaptação e mal-estar ${ }^{27}$.

A OMS é composta por três principais órgãos: a Assembleia Mundial da Saúde, o Conselho Executivo e o Secretariado. A tarefa legislativa fica a cargo da Assembleia, que tem competência para elaborar convenções - que por sua vez devem ser internalizadas pelos Estados - e regulamentos internacionais - que entram automaticamente em vigor nos Estados, salvo se fizerem reserva ou rejeição expressas -, além das recomendações, sem poder vinculante. A instituição também tem uma sistemática de monitoramento do cumprimento de tal normativa pelos Estados, através do envio de relatórios anuais, estatísticos e epidemiológicos. Cria-se então um verdadeiro corpus juris especializado, com o fim de salvaguardar o direito humano à saúde.

Não se pode descurar do papel fundamental desempenhado pela Declaração Universal de Direitos do Homem, que surge no momento imediatamente subsequente, em forma de resolução aprovada unanimemente por 48 Estados que compunham a Assembleia Geral da ONU. Esse documento delineou direitos e liberdades individuais e sociais que, em conjunto, conduzem ao ideal de dignidade humana ${ }^{28}$; foi

\footnotetext{
${ }^{26}$ Cumpre mencionar que na Constituição da OMS, de 22 de julho de 1946, a qual entrou em vigor em 7 de abril de 1948, consta em seu Preâmbulo que "A saúde é um estado de completo bem-estar físico, mental e social, e não consiste apenas na ausência de doença ou de enfermidade. A saúde de todos os povos é essencial para conseguir a paz e a segurança e depende da mais estreita cooperação dos indivíduos e dos Estados". Tem a OMS objetivo de que todos os povos alcancem o mais elevado nível de saúde possível e, para isso, atuará como autoridade diretora e coordenadora dos trabalhos internacionais no domínio da saúde, estabelecendo e mantendo a colaboração entre Estados. (GELIS FILHO, Antônio. Globalização, serviços de saúde e Direito Internacional. Revista de Direito Sanitário, São Paulo, v. 2, n. 3, p. 64, nov. 2001. Conferir, também a CONSTITUIÇÃO da Organização Mundial da Saúde (OMS/WHO). Disponível em: $<$ http://www.onuportugal.pt/oms.pdf>. Acesso em: 05 maio 2013).

${ }^{27}$ REZENDE, Ana Lúcia Magela, op. cit., p. 86.

${ }^{28}$ De acordo com a Declaração Universal de Direitos do Homem, "Toda pessoa tem direito a um nível de vida suficiente para Ihe assegurar e a sua família a saúde e o bem-estar, principalmente quanto à alimentação, ao vestuário, ao alojamento, à assistência médica e ainda quanto aos serviços sociais necessários; e tem direito a segurança no desemprego, na doença, na invalidez, na viuvez, na velhice ou noutros casos de perda de meios de subsistência por circunstâncias independentes da sua vontade". (DECLARAÇÃO Universal dos Direitos do Homem. Disponível em: <http://www.dhnet.org.br/direitos/deconu/textos/onu3. htm\#Artigo23>. Acesso em: 05 mai. 2013).
} 
nessa declaração que a saúde passou a ser reconhecida como um direito, ainda que de forma indireta. Muito embora a Declaração Universal de Direitos do Homem sirva como "imagem do que a comunidade internacional entende por direitos humanos", sem força vinculante, é inegável seu impacto sobre as constituições, legislações e jurisprudências nacionais, bem como nas demais resoluções da ONU e em tratados internacionais, que ostentam a obrigatoriedade dos Estados signatários de concretização dos direitos e liberdades nela consagrados ${ }^{29}$.

A partir da Declaração de 1948, efetivamente caracterizada pela universalidade dos direitos fundamentais reconhecidos a todos os indivíduos e cuja preocupação ultrapassa os limites territoriais e influencia todas as cartas constitucionais elaboradas no período pós-guerra, surgiram outros importantes documentos que têm o condão de dar mais força ao conteúdo dos direitos humanos ${ }^{30}$.

Nesse ambiente surgem, em 1966, dois importantes instrumentos celebrados no âmbito da ONU que, segundo Marco Torronteguy, efetivamente positivaram os direitos humanos ${ }^{31}$. Foram eles o Pacto Internacional sobre os Direitos Civis e Políticos ${ }^{32}$, direcionado à proteção dos direitos individuais, e o Pacto Internacional sobre os Direitos Econômicos, Sociais e Culturais ${ }^{33}$, endereçado aos Estados, sendo estes obrigados a implementar e assegurar referidos direitos. O primeiro tem em vista a proteção da vida e sua dignidade, particularmente contra a ingerência estatal, além da participação popular na gestão da sociedade. O segundo orienta-se ao bem-estar social, incluindo medidas relacionadas à melhoria contínua das condições de vida. Nesse sentido, faz referência à existência decente de todas as pessoas e a um nível de vida adequado em que se incluem medidas, por parte dos Estados-Partes, relacionadas à alimentação, à moradia e à medicalização. Estabelece, ademais, que os Estados-Partes reconhecem o direito de toda pessoa de desfrutar o mais elevado nível de saúde física e mental. As medidas para assegurar o pleno exercício desse direito incluem, entre outras, a prevenção e o tratamento das doenças epidêmicas, endêmicas, profissionais e outras, bem como a luta contra as mesmas, além da criação de condições que

\footnotetext{
${ }^{29}$ GODINHO, Fabiana de Oliveira. op., cit., p. 11-14. Nesse sentido, TRINDADE, Antônio Augusto Cançado. Princípios do direito internacional contemporâneo. Brasília: UnB, 1981. p. 227; RAMOS, André de Carvalho, op. cit., p. 51; TORRONTEGUY, Marco Aurélio Dantas. O direito humano à saúde no direito internacional: efetivação por meio da cooperação sanitária. Tese (Doutorado). 2010. p. 80. Disponível em: <http://www. teses.usp.br/teses/disponiveis/2/2140/tde-14032011-154326/fr.php>. Acesso em: 01 ago. 2013.

${ }^{30}$ SARLET, Ingo Wolfgang. A eficácia dos direitos fundamentais: uma teoria geral dos direitos fundamentais na perspectiva constitucional. 10. ed. rev., atual. e ampl. Porto Alegre, RS: Livraria do Advogado, 2011. p. 56; DALLARI, Sueli. 0 direito à saúde. Revista Saúde Pública, São Paulo, v. 22, n. 1, p. 57 ss., fev. 1998.

${ }^{31}$ TORRONTEGUY, Marco Aurélio Dantas, op. cit., p. 84.

${ }^{32}$ PACTO Internacional sobre os Direitos Civis e Políticos. Disponível em: <http://portal.mj.gov.br/sedh/ct/ legis_intern/pacto_dir_politicos.htm>. Acesso em: 11 jul. 2013.

${ }^{33}$ PACTO internacional sobre direitos econômicos, sociais e culturais. Disponível em: <http://www.oas.org/ dil/port/1966\%20Pacto\%20Internacional\%20sobre\%20os\%20Direitos\%20Econ\%C3\%B3micos,\%20Sociais\%20e\%20Culturais.pdf>. Acesso em: 11 jun. 2013.
} 
assegurem a todos assistência e serviços médicos em caso de enfermidade. À vista do exposto, pode-se afirmar que os direitos e garantias consignados nos referidos pactos remetem-se inevitavelmente à tutela da saúde por considerar os valores bem-estar e existência digna ${ }^{34}$.

Consecutivamente, em 1969 surgiu, no âmbito da OMS, através da 22a Assembleia Mundial de Saúde, o Novo Regulamento Sanitário Internacional (RSI), ou seja, um instrumento jurídico internacional sobre saúde pública, juridicamente vinculante para todos os Estados-Partes, cuja finalidade é, principalmente, restringir os riscos à saúde pública, proporcionando a máxima segurança contra a propagação internacional de doenças e um mínimo de obstáculos para o trânsito internacional de pessoas e de bens ${ }^{35}$. Referido RSI passou, a partir de 1995, a ser particularmente revisado em razão do ressurgimento de antigas e do aparecimento de novas doenças, sendo finalmente substituído por um novo regulamento em 2005 - a partir de quando há a permissão à OMS identificar alarmes de epidemias e iniciar processos de investigações e planos de ação em diferentes países, mesmo sem comunicação oficial voluntária do Estado-Membro. Cuida-se, segundo Carolina B. Gomes e Larissa de P. Gonzaga e Castro, da internacionalização do sistema de vigilância em saúde, indicando que os países não podem ignorar ou esconder informações a respeito de problemas sanitários. Ademais, de acordo com o regulamento em referência, compete a cada um dos Estados estruturar um sistema de identificação e notificação de eventos e as formas de atuação, sob pena de responsabilidade ${ }^{36,37}$.

Percebe-se que a discussão a respeito do direito à saúde e sua efetiva operacionalização avançaram especialmente a partir do final do século XIX e início do século XX, com a sociedade marcada pelo aprofundamento da globalização (nesta incluída a globalização das doenças) e por novos desafios no campo das ciências e, inclusive, da saúde coletiva. Sendo assim, foi considerada a época em que foram descobertos muitos agentes infecciosos e seus modos de transmissão, desenvolvendo-se soros, vacinas e medicamentos específicos e mais adequados, bem como o saneamento de cidades e a criação de leis que pudessem repercutir na melhora das condições de saúde da população. Esse período caracterizou-se fundamentalmente pela alusão expressa ao direito à saúde, cuja titularidade deixou de ser individual, e pela mudança de paradigma conceitual conferido pela OMS,

\footnotetext{
${ }^{34}$ Segundo André de Carvalho Ramos, a Declaração Universal de Direitos Humanos mais os dois pactos formam a Carta Internacional dos Direitos Humanos porque possuem alcance universal e abrangem várias espécies de direitos. Posteriormente, muitos outros tratados e protocolos adicionais foram incorporados ao rol de direitos humanos (RAMOS, André de Carvalho. op. cit., p. 52).

${ }^{35}$ MÍNGUEZ GONZALO, Miguel, op. cit., p. 241; AITH, Fernando. Curso de direito sanitário: a proteção do direito á saúde no Brasil. São Paulo: Quartier Latin, 2007. p. 279.

${ }^{36}$ BATISTA, Vanessa Oliveira, op. cit., p. 24; GOMES, Carolina B.; CASTRO, Larissa de P. Gonzaga e, op. cit., p. 139-140; FERREIRA, Fátima de Paula; CASTRO, Larissa de Paula Gonzaga. op. cit., p. 67-71; 141-148.

${ }^{37}$ No Brasil, compete à Secretaria de Vigilância Sanitária (SVS) transmitir esses dados para a OPAS e a OMS.
} 
identificando a saúde não apenas como ausência de doença, mas como bem-estar integral. Assinalou, ademais, o estabelecimento de acordos entre países e a reunião dos Estados em um número crescente de organizações internacionais que tiveram e ainda têm importante papel na elaboração de diretrizes, estratégias e políticas públicas no âmbito sanitário ${ }^{38}$.

Nesse contexto, importância fundamental possui a Declaração de Alma-Ata ${ }^{39}$, aprovada em 1978 na cidade de Alma-Ata, na antiga União Soviética, no âmbito da Conferência Internacional sobre Cuidados Primários de Saúde realizada pela OMS. Trata-se de mais um documento internacional sobre a saúde, expressando “(...) a necessidade de ação urgente de todos os governos, de todos os que trabalham nos campos da saúde e do desenvolvimento e da comunidade mundial para promover a saúde de todos os povos do mundo" ${ }^{40}$. Segundo a conferência, a saúde, sua promoção e proteção são imprescindíveis para o desenvolvimento econômico e social contínuo, além de contribuírem para a melhor qualidade de vida e para a paz mundial. A Declaração de Alma-Ata proclamou o aperfeiçoamento do acesso aos serviços de saúde, bem como o trabalho de cooperação com outros setores da sociedade, indicando a necessidade de mudança nas relações de poder entre os prestadores e os usuários de tais serviços. Portanto, um dos princípios mais importantes proclamados nessa ocasião foi o do envolvimento e da participação efetiva da população como um todo na promoção da saúde. Ademais, representou o ponto de partida das conferências internacionais sobre a promoção de saúde e de cujo contexto surgiram outros importantes documentos internacionais ${ }^{41}$.

Outrossim, surgiram outras conferências a partir das quais foram elaboradas declarações de intenção, sem caráter vinculante, mas identicamente denotando a preocupação internacional com a saúde e direcionando as ações dos Estados no âmbito sanitário. É o caso da Carta de Ottawa para a promoção da saúde (1986); da Declaração da Conferência Internacional de Promoção da Saúde (1992); da Declaração de Viena na Conferência Mundial sobre Direitos Humanos (1993); da Carta do Caribe para a Promoção da Saúde (1993); da Declaração de Jacarta sobre Promoção da Saúde pelo Século XXI adentro (1997); da Carta de Bangkok na VI Conferência

\footnotetext{
${ }^{38}$ Nesse sentido, BERLINGUER, Giovanni. Globalização e saúde global. Estudos Avançados, São Paulo, v. 13, n. 35, p. 25 jan./abr. 1999. Disponível em: <http://www.scielo.br/pdf/ea/v13n35/v13n35a03.pdf>. Acesso em: 22 jul. 2013.

${ }^{39}$ DECLARAÇÃO de Alma-Ata. Disponível em: <http://www.dhnet.org.br/direitos/sip/onu/saude/almaata. htm>. Acesso em: 06 mar 2015.

${ }^{40}$ BRASIL. Ministério da Saúde. Direito sanitário e saúde pública: manual de atuação jurídica em saúde pública e coletânea de leis e julgados em saúde. Brasília-DF: Síntese, 2003. v. 2, p. 35.

${ }^{41}$ BRASIL. Ministério da Saúde. Direito sanitário e saúde pública: manual de atuação jurídica em saúde pública e coletânea de leis e julgados em saúde, cit., p. 35; WESTPHAL, Marcia Faria. Promoção da saúde e a qualidade de vida. In: ROCHA, Aristides Almeida; CESAR, Chester Luiz Galvão. Saúde Pública: bases conceituais. São Paulo: Atheneu, 2008. p. 153-154.
} 
Internacional sobre Promoção da Saúde em Bangkok (2005); entre outras ${ }^{42}$. Quanto à Carta de Ottawa, emanada da Primeira Conferência Internacional de Promoção à Saúde, ela é igualmente fundamental, sobretudo no que se refere ao reforço dado à importância da ação política na promoção da saúde, um processo através do qual a própria população se capacita e busca meios para conseguir identificar e controlar os fatores de risco que possam interferir em sua qualidade de vida, especialmente através de políticas públicas destinadas ao seu bem-estar integral ${ }^{43}$.

Todas as conferências e os documentos delas resultantes estabelecem medidas para implementação da saúde de todos os povos, entre as quais se incluem imunização contra as principais doenças infecciosas, prevenção e controle de doenças endêmicas, tratamento apropriado das doenças comuns e gerência sobre acidentes e distribuição de medicamentos. Cumpre fazer referência, nesse tocante, à Conferência Internacional de Autoridades Regulatórias promovida a cada dois anos pela OMS abordando temas afetos à saúde coletiva com repercussão multilateral, como, entre outros, as boas práticas de regulação, a certificação de produtos objetos de comércio internacional, a utilização de medicamentos, medicamentos essenciais e medicamentos adulterados, as zonas de livre comércio e os esforços regionais de regulação do tabaco ${ }^{44}$.

Há que se fazer alusão, ainda, à importância que possui a Organização Mundial do Comércio $(\mathrm{OMC})$ na sua intervenção através de acordos multilaterais firmados no contexto do comércio internacional, incluindo o comércio de produtos de interesse para a saúde. Desse modo, a OMC inevitavelmente interfere no ambiente sanitário. Nesse sentido podem ser citados, por exemplo, o Acordo sobre Aplicação de Medidas Sanitárias e Fitossanitárias (AMSF) - que dispõe sobre a introdução, o estabelecimento e a disseminação de praga ou doença no território do país importador, com atenção aos efeitos adversos resultantes do uso de aditivos e da presença de contaminantes, toxinas ou organismos patogênicos em alimentos

\footnotetext{
${ }^{42}$ Quanto a isso, podem ainda ser citadas a I Conferência Internacional sobre Promoção da Saúde em Ottawa (1986); a II Conferência Internacional sobre Promoção da Saúde em Adelaide (1988); a III Conferência Internacional sobre Promoção da Saúde em Sundsvall (1991); a Conferência Internacional sobre Promoção da Saúde de Bogotá (1992); a Primeira Conferência de Promoção da Saúde no Caribe, em Port of Spain (1993); a IV Conferência Internacional sobre Promoção da Saúde em Jacarta (1997); a Rede de Megapaíses para Promoção da Saúde, Suíça (1998); a V Conferência Internacional sobre Promoção da Saúde na Cidade do México (2000); a III Conferência Latino-Americana de Promoção da Saúde e Educação para a Saúde, em São Paulo (2002); a VI Conferência Internacional sobre Promoção da Saúde em Bangkok (2005); a Conferência Internacional de Saúde para o Desenvolvimento, em Buenos Aires (2007). (ÁLVAREZ, Maria Andrich de. Alimentos: salud y consumo. Marco regulatório, algunas normas y las nuevas situaciones vinculadas con la seguridad alimentaria. In: FARINATI, Alicia (Coord.). Salud, derecho y equidad: princípios consitucionales. Políticas de salud. Bioética. Alimentos y desarrollo. Buenos Aires: Ad Hoc, 2001. p. 216-217.) Ver também CARTA dos direitos fundamentais da União Europeia. Disponível em: <http://europa.eu.int/eur-lex/pri/pt/oj/ dat/2000/c364/c36420001218pt00010022.pdf>. Acesso em: 05 maio 2013.

${ }^{43}$ WESTPHAL, Márcia Faria, op. cit., p. 155.

${ }^{44}$ LUCCHESE, Geraldo. A internacionalização da regulamentação sanitária. Ciência \& Saúde Coletiva, Rio de Janeiro, v. 8, n. 2, p. 551, 2003. Disponivel em: <http://www.scielo.br/scielo.php?script=sci_arttext\&pid=S1413-81232003000200016>. Acesso em: 05 ago. 2013.
} 
e ração animal - e o Acordo sobre Barreiras Técnicas ao Comércio (BTC) - que visa, entre outros aspectos, à prevenção de práticas fraudulentas relativas a todos os produtos de fluxo internacional e à proteção da saúde e segurança humanas ${ }^{45}$. Há que se fazer menção, outrossim, ao Acordo Geral sobre o Comércio de Serviços (AGCS) e ao Acordo sobre os Aspectos dos Direitos da Propriedade Intelectual Relacionados ao Comércio (TRIPS, na sigla em inglês), este último prevendo o direito dos Estados signatários de instaurar um corpo de normas, em seus contextos, que tenha por fim a proteção da saúde e a nutrição públicas, bem como conter abusos no âmbito da propriedade intelectual, do comércio ou da transferência internacional de tecnologia ${ }^{46}$.

Outros documentos mais, de cunho internacional, demonstram a inquietação com a segurança sanitária e os riscos à saúde, entre os quais a Convenção da Basileia, que define diretrizes para o transporte transfronteiriço de cargas perigosas; o Programa Internacional de Controle de Substâncias Químicas, que busca avaliar o risco de substâncias químicas utilizadas industrialmente; e o Protocolo de Cartagena, que faz parte da Convenção da Diversidade Biológica e busca protegê-la dos riscos potenciais relacionados à moderna biotecnologia ${ }^{47}$.

Da mesma maneira, diversos outros organismos e agências internacionais estão direta ou indiretamente implicados nas questões sanitárias mundiais e participam, de alguma forma, da elaboração de políticas internacionais de saúde. Entre esses organismos, estão o Banco Mundial, o Fundo Monetário Internacional (FMI), o Programa das Nações Unidas para o Desenvolvimento (PNUD), o Fundo de Populações das Nações Unidas (UNFPA) e o Fundo das Nações Unidas para a Infância (Unicef) ${ }^{48}$.

Ademais, é de se dar destaque, em nível regional, à Declaração Americana dos Direitos e Deveres do Homem, que entrou em vigor poucos meses depois da Declaração Universal de 1948. Citada declaração, diversamente, faz referência

\footnotetext{
${ }^{45}$ FERREIRA, Fátima de Paula; CASTRO, Larissa de Paula Gonzaga. op. cit., p. 73-74.

${ }^{46}$ Segundo Thomas Bréger, acordos multilaterais no âmbito da propriedade intelectual geraram efeitos negativos da interferência do direito da OMC no campo da saúde, especialmente relacionadas ao acesso dos países em desenvolvimento aos medicamentos que combatem, por exemplo, a AIDS. Haveria, desse maneira, a proteção dos interesses econômicos em detrimento da satisfação das necessidades sanitárias fundamentais das populações mais pobres (BRÉGER, Thomas. A saúde diante da globalização e das forças do mercado. Revista de Direito Sanitário, São Paulo, v. 13, n.2, p. 67, jul./out. 2012). A respeito do assunto, e particularmente sobre patentes de medicamentos no âmbito do Mercosul, conferir SEPULCRI, Nayara Tataren. Propriedade intelectual e desenvolvimento: uma análise sobre a problemática das patentes farmacêuticas no Mercosul. p. 35-68. In: FRIEDRICH, Tatyana Scheila; BACELLAR FILHO, Romeu Felipe. Aspectos jurídicos da aproximação dos países com vistas ao desenvolvimento. Curitiba: Íthala, 2010. E sobre os ajustes multilaterais conferir também LUCCHESE, Geraldo, op. cit., p. 527-555.

${ }^{47}$ LUCCHESE, Geraldo, op. cit., p. 549-553.

${ }^{48}$ Conferir, nesse sentido, SOARES, Guido F. S. Aspectos internacionais da segurança sanitária num mundo globalizado: o regulamento sanitário internacional e a organização mundial do comércio. In: SEMINÁRIO INTERNACIONAL DE DIREITO SANITÁRIO, 5., 1999, São Paulo, Anais... São Paulo: Universidade de São Paulo, 1999, p. 151-175; GELIS FILHO, Antônio. op. cit., p. 63-64; e BERLINGUER, Giovanni, op. cit., p. 26.
} 
expressa ao direito à saúde, em seu artigo 11, mencionando que "toda pessoa tem direito a que sua saúde seja resguardada por medidas sanitárias e sociais relativas a alimentação, roupas, habitação e cuidados médicos correspondentes ao nível permitido pelos recursos públicos e os da coletividade" ${ }^{\text {"49 }}$. Além da menção explícita ao direito, remete-se aos meios ou fatores condicionantes da saúde, cujas prestações devem ser imediatas.

Nesse mesmo circuito, a Convenção Americana de Direitos Humanos (1969) prevê, entre outros direitos e garantias ali consagrados, o direito à vida e à integridade pessoal (física, psíquica e moral), além da honra e dignidade. Esses direitos, segundo a convenção, devem ser protegidos por lei e estar relacionados ao direito à vida, desde o momento da concepção, não podendo ninguém ser deles privado arbitrariamente ${ }^{50}$. De acordo com Marco Torronteguy, aludida convenção faz referência à defesa da saúde pública como justificativa para eliminação excepcional de outros direitos por ela reconhecidos. Significa dizer que, no conflito entre os valores ali consagrados, o direito à saúde poderá prevalecer ${ }^{51}$. Segundo o autor mencionado, a Convenção Americana sobre Direitos Humanos atribuiria ao direito à saúde preponderância em relação a outros direitos sociais.

Igualmente no âmbito das Américas e em nível intergovernamental, a OMS atua através da Organização Pan-Americana de Saúde (OPAS). É por meio dessa organização que a OMS relaciona-se com o Brasil. A OPAS tem como objetivos fundamentais a promoção e coordenação de esforços para combater enfermidades, aumentar a expectativa de vida e promover a saúde física e mental das pessoas nos países americanos. Entre outras importantes questões relacionadas à saúde coletiva, a OPAS preocupa-se especialmente com os insumos essenciais à saúde e com a tecnologia, buscando implementar mecanismos para garantir o uso seguro de medicamentos, inclusive através de metodologias para combater a comercialização de medicamentos falsificados. Importa fazer alusão à Conferência Pan-Americana de Harmonização da Regulamentação Farmacêutica, realizada pela OPAS desde 1997 seguindo a sistemática da OMS. Estão na pauta dessas conferências, entre outros assuntos, as boas práticas de fabricação e as boas práticas clínicas, a exigência de testes de bioequivalência e biodisponibilidade, as condições de venda dos produtos, o fortalecimento das agências reguladoras, a classificação e a contrafação de medicamentos ${ }^{52}$.

\footnotetext{
${ }^{49}$ TRINDADE, Antonio Augusto Cançado. A proteção internacional dos direitos humanos: fundamentos jurídicos e instrumentos básicos. São Paulo: Saraiva, 1991. p. 328

${ }^{50}$ Convenção Americana de Direitos Humanos: Pacto São José da Costa Rica de 1969 (adotada e aberta para assinatura na Conferência Especializada Interamericana sobre Direitos Humanos, em San José de Costa Rica em 22 de novembro de 1969). Ratificada pelo Brasil em 25 de setembro de 1992. CONVENÇÃO Americana de Direitos Humanos: Pacto San Jose da Costa Rica. Disponível em: <http://www.pge.sp.gov.br/ centrodeestudos/bibliotecavirtual/instrumentos/sanjose.htm>. Acesso em: 05 maio 2013.

${ }^{51}$ TORRONTEGUY, Marco Aurélio Dantas, op. cit., p. 104.

${ }^{52}$ LASMAR, Jorge Mascarenhas; CASARÕES, Guilherme Stolle Paixão e, op. cit., p. 116; BATISTA, Vanessa Oliveira, op. cit., p. 28; ROSENBERG, Félix J. Mecanismos legais de controle da segurança do medicamento. Revista de Direito Sanitário, São Paulo, v. 2, n. 1, p. 100, mar. 2001.
} 
Em âmbito regional um pouco mais restrito, pode-se citar como normas relativas à operacionalização do direito à saúde aquelas oriundas dos blocos econômicos, como ocorre no âmbito da União Europeia (UE) e do Mercado Comum do Cone Sul (Mercosul). O Mercosul, do qual faz parte o Brasil, inaugurado em 1994 através do Tratado de Assunção, caracteriza-se como uma união aduaneira com o objetivo de se constituir um mercado comum, com a livre circulação de pessoas, bens e serviços. E é por essa razão que as normas oriundas do Mercosul e com validade no território nacional devem promover não apenas a regulação das atividades econômicas que repercutem na qualidade dos produtos e das informações a seu respeito, mas devem garantir as condições de saúde e a segurança da população envolvida ${ }^{53}$. Assim, inúmeras são as regulamentações sanitárias que vigoram na esfera do Mercosul. E o trabalho de harmonização desses regulamentos é realizado no recinto das comissões temáticas que constituem os subgrupos de trabalho. No Brasil, a área de Relações Internacionais da Agência Nacional de Vigilância Sanitária (Anvisa) concentra-se no Subgrupo n. 3 (Regulamentos Técnicos e Procedimentos de Avaliação da Conformidade) e no Subgrupo 11 (Saúde), competindo a este último a vigilância em saúde, produtos para a saúde e serviços de atenção à saúde ${ }^{54}$. Este último grupo possui importância fundamental na medida em que, através de suas resoluções, busca harmonizar as legislações dos Estados-Partes relativas a bens, serviços, matérias-primas e produtos da área da saúde, além de critérios para a vigilância epidemiológica e o controle sanitário - tudo isso com o propósito de promover e proteger a saúde e a vida das pessoas e eliminar os obstáculos ao comércio regional ${ }^{55}$. Nesse sentido, ganham destaque as normas destinadas aos cidadãos do Mercosul relativas aos aspectos sanitários e de saúde e, em particular, à circulação transfronteiriça de medicamentos, como é o caso das Resoluções GMC ns. 66/2000 e 74/2000. Com idêntico destaque, encontra-se o Decreto n. 16/2012 que dispõe a respeito da rede de pontos focais de saúde para prevenção e combate à falsificação de medicamentos e produtos médicos no Mercosul ${ }^{56}$. E, assim como acontece no ambiente da OMS e da OPAS, no Mercosul existe o Fórum Permanente para o Trabalho em Saúde, institucionalizado pela Portaria GM n. 929/2006, constituindo-se um espaço de diálogo e cooperação entre gestores e trabalhadores de saúde, com a apresentação de propostas que ajudam na formulação de políticas para gestão do trabalho e da

${ }^{53}$ A respeito da proteção dos consumidores no Mercosul ver TERUCHKIN, Sônia Unikowsky. A proteção dos consumidores no Mercosul: algumas considerações. Indicadores Econômicos FEE, v. 25, n. 4, p. 278-293, 1998. E a respeito de preocupações sociais no âmbito do Mercosul (além das econômicas) conferir KOLLING, Gabriele; MASSAÚ, Guilherme Camargo. Cidadania supranacional e o direito à saúde. Ciências Sociais Aplicadas em Revista, Marechal Cândido Rondon, v. 10, n. 19, p. 44 e ss., 2. sem. 2010.

${ }^{54}$ PEREIRA, Bruno Yepes, op. cit., p. 150; LUCCHESE, Geraldo, op. cit., p. 551; FERREIRA, Fátima de Paula; CASTRO, Larissa de Paula Gonzaga. op. cit., p. 76-78.

${ }^{55}$ PORTAL da saúde. Subgrupo de Trabalho n. 11. Disponível em: <http://portal.saude.gov.br/portal/saude/ profissional/visualizar_texto.cfm?idtxt=27171>. Acesso em: 25 jul. 2013.

${ }^{56}$ Nesse sentido conferir: CARTILLA del ciudadano del Mercosur. Disponível em: <http://www.mercosur.int/ innovaportal/file/2431/1/cartilla_ciudadano_mercosur___esp.pdf>. Acesso em: 25 jul. 2013. 
educação em saúde da população do Mercosul. É composto por diversos órgãos e instituições, entre os quais os ministérios da Saúde, da Educação e do Emprego, a Anvisa, a Fundação Oswaldo Cruz (Fiocruz), a OPAS e entidades sindicais, científicas e estudantis ${ }^{57}$.

Verifica-se, destarte, que a concepção de saúde modifica-se com o devir da história, passando de prevenção e cura de doenças a um conceito amplo, particularmente formulado no âmbito da OMS e reiterado nos principais documentos internacionais ${ }^{58}$. Observa-se, também, que as medidas sanitárias para prevenção e contenção das enfermidades aparecem nos primeiros momentos da civilização, mas a saúde como um direito exsurge apenas no século XIX - a princípio de forma bastante acanhada e, posteriormente, por meio da reunião de esforços entre diversos países, invadindo a maioria das constituições e legislações internas destes, como ocorreu no Brasil. Não obstante o século XXI continue sendo caracterizado pela mundialização, inclusive de novas e de velhas doenças, o direito à saúde constitui um dos direitos fundamentais do homem, ensejando a operacionalização de medidas multilaterais destinadas a efetivá-lo.

\section{Considerações finais}

Observa-se, pelo exposto, que a ideia de globalização da doença e daquilo que se denomina direito à saúde - ou de um estado completo de bem-estar físico-mental e social do indivíduo - não é recente. Primeiro, vê-se a difusão dos problemas relacionados à saúde a partir do próprio nomadismo primitivo, aperfeiçoando-se por meio do alargamento das fronteiras - o que aconteceu graças, sobretudo, aos interesses econômicos dos países, na forma de colonização e guerra e com o mercantilismo-capitalismo. Foi particularmente com o advento da globalização e da implementação de novas tecnologias que os problemas sanitários se tornaram ainda mais evidentes.

Os cuidados com a saúde, por sua vez, estiveram relacionados, em um primeiro momento, a procedimentos costumeiros, mágicos ou religiosos, cabendo à Igreja um papel extremamente importante nesse contexto. $\mathrm{O}$ Estado passou a interferir timidamente, especialmente com medidas de isolamento e de proibição do trânsito de bens e pessoas em suas fronteiras. Tais medidas acabaram sendo adotadas pela grande maioria dos Estados afetados por epidemias, principalmente na Europa. De uma intervenção sanitária acanhada, o Estado passou a intervir mais

\footnotetext{
${ }^{57}$ PORTAL da Saúde. Disponível em: <http://portal.saude.gov.br/portal/saude/profissional/area.cfm?id_ area=1111>. Acesso em: 05 de ago. 2013.

${ }^{58}$ Esse conceito amplo é mencionado por Sueli Gandolfi Dallari nos seguintes termos: “(...) o conceito de saúde adotado nos documentos internacionais relativos aos direitos humanos é o mais amplo possível, abrangendo desde a típica face individual do direito subjetivo à assistência médica em caso de doença, até a constatação da necessidade do direito do Estado ao desenvolvimento, personificada no direito a um nível de vida adequado à manutenção da dignidade humana". (DALLARI, Sueli Gandolfi. Direito sanitário, cit., p. 47.)
} 
ativamente, principalmente porque os problemas relativos à saúde traziam prejuízos para os setores produtivos. Desse modo, passou a atuar diretamente no âmbito sanitário, inclusive através da distribuição de produtos de saúde e, particularmente, através de instrumentos normativos que apareceram, nesse contexto, com propósitos eminentemente utilitaristas.

Em que pese a ideia de globalização da doença e das primeiras tentativas multilaterais de contenção dos riscos à saúde coletiva, com o surgimento de importantes documentos de direitos, foi somente no século XIX, com o aparecimento das grandes epidemias que ultrapassavam os limites geográficos dos Estados e a necessidade de sua contenção e prevenção, que se buscou a cooperação internacional, inaugurando-se as convenções e conferências sanitárias internacionais e a criação dos primeiros organismos internacionais preocupados com a saúde coletiva. De importância fundamental, inclusive para consolidar uma nova concepção de saúde, dissociada da ideia de ausência de doença e relacionada à ideia de saúde integral (física, mental e social), foi a criação da OMS. E, a partir de sua constituição, o direito à saúde passa a ser desenhado, determinando-se aos governos a responsabilidade pela saúde de seus povos, com a adoção de medidas sanitárias e sociais adequadas.

Não se pode deixar de assinalar que a harmonização das normas internacionais relacionadas à saúde, bem como aos produtos e serviços sanitários, tem por fim a consecução do direito à saúde e de todas as garantias assinaladas nos principais documentos que a relacionam, direta ou indiretamente - como é o caso das declarações de direitos do homem e do cidadão e da Constituição da OMS, que têm por igual fim, no âmbito da globalização e da regionalização, a higidez do comércio internacional. São exemplos dessa última circunstância desde os diferentes acordos e regulamentações relacionados à sanidade de bens de trânsito transfronteiriço até as normas relacionadas à propriedade industrial.

Além da OMS, no âmbito das Américas aparece a OPAS e, regionalmente, o Mercosul. A partir destas organizações especializadas, surgem orientações e regulamentações que direcionam as ações e políticas dos Estados-Membros no tocante à saúde coletiva e aos problemas relacionados a ela. Os ajustes firmados entre os Estados, as declarações de direitos, os tratados internacionais e demais documentos internacionais que emanam desses e de outros organismos internacionais inevitavelmente influenciam as constituições, legislações e jurisprudências dos Estados, e suas diretrizes são incorporadas a elas. Reconhecem-se os direitos, cuja concretização é imposta aos Estados signatários.

Nesse tocante, e à guisa de conclusão, no Brasil, a Constituição Federal de 1988 refere-se ao direito à saúde de forma mediata ao prever o direito à vida e à dignidade humana - fundamentos inevitavelmente relacionados à saúde - e de forma imediata nos artigos $6^{\circ}$ e 196. Reconhece, em seu texto, a definição de saúde 
delineada pela OMS e, a partir das diretrizes da organização, estabelece ações e políticas do poder público para implementação do referido direito. Reflexamente, e à vista dos demais documentos internacionais - como é o caso, por exemplo, do RSI e das regulamentações emanadas dos grupos de trabalho do Mercosul -, harmoniza sua legislação e suas políticas sanitárias para prevenir e afastar os riscos e efetivamente implementar o direito à saúde.

Verifica-se que a saúde galgou o status de direito fundamental do homem, sendo reconhecida nos principais documentos internacionais e nas cartas políticas dos Estados. A partir disso, reconheceu-se igualmente a importância dos esforços multilaterais para a promoção da saúde coletiva e a contenção dos riscos sanitários, criando-se mecanismos de ação conjunta e, principalmente, normas que passaram a ser incorporadas pelos Estados para melhoria das condições de saúde e de vida da população.

\section{Referências}

AITH, Fernando. Curso de direito sanitário: a proteção do direito á saúde no Brasil. São Paulo: Quartier Latin, 2007.

ÁLVAREZ, Maria Andrich de. Alimentos: salud y consumo. Marco regulatório, algunas normas y las nuevas situaciones vinculadas con la seguridad alimentaria. In: FARINATI, Alicia (Coord.). Salud, derecho y equidad: princípios consitucionales. Políticas de salud. Bioética. Alimentos y desarrollo. Buenos Aires: Ad Hoc, 2001.

BACELLAR FILHO, Romeu Felipe. Aspectos jurídicos da aproximação dos países com vistas ao desenvolvimento. Curitiba: İthala, 2010.

BATISTA, Vanessa Oliveira. A proteção internacional do direito à saúde. Disponível em: <www.estig.ipbeja.pt/ ac_direito/Vanessa.doc>. Acesso em: 22 jul. 2013.

BERLINGUER, Giovanni. Globalização e saúde global. Estudos Avançados, São Paulo, v. 13, n. 35, p. 21 -38 jan./abr. 1999. Disponível em: <http://www.scielo.br/pdf/ea/v13n35/v13n35a03. pdf $>$. Acesso em: 22 jul. 2013.

BRASIL. Ministério da Saúde. Direito sanitário e saúde pública: manual de atuação jurídica em saúde pública e coletânea de leis e julgados em saúde. Brasília-DF: Síntese, 2003. v. 2.

BRÉGER, Thomas. A saúde diante da globalização e das forças do mercado. Revista de Direito Sanitário, São Paulo, v. 13, n.2, p. 64-75, jul./out. 2012.

BRUYN JÚNIOR, Herbert Cornélio Pieter de. A proteção da liberdade e o controle sanitário. Revista de Direito Sanitário, São Paulo, v. 3, n. 2, jul. 2002.

CAMPOS, Gastão Wagner de Sousa. A saúde pública e a defesa da vida. 3.ed. São Paulo: Hucitec, 2006. 
CARTILlA del ciudadano del Mercosur. Disponível em: <http://www.mercosur.int/ innovaportal/file/2431/1/cartilla_ciudadano_mercosur_-_esp.pdf>. Acesso em: 25 jul. 2013.

COMITÊ Internacional da Cruz Vermelha. Disponível em: <http://www.icrc.org/por/ who-we-are/history/overview-section-history-icrc.htm>. Acesso em: 04 maio 2013.

COMPARATO, Fábio Konder. A afirmação histórica dos direitos humanos. 7. ed. São Paulo: Saraiva, 2010.

COSTA, Geraldo de Faria Martins. A proteção da saúde do consumidor na ordem econômica: direito subjetivo público. Revista de Direito do Consumidor, n. 21, p. 132-141, jan./mar. 1997.

DALLARI, Sueli Gandolfi. Direito sanitário. In: ARANHA, Márcio Iorio (Coord). Direito sanitário e saúde pública. Coletânea de Textos. Ministério da Saúde. Secretaria de Gestão do Trabalho e da Educação na Família. Departamento de Gestão da Educação da Saúde. Brasília: Ministério da Saúde, 2003.

. O direito à saúde. Revista Saúde Pública, São Paulo, v. 22, n. 1, p. 57-63, fev. 1998.

. Os Estados brasileiros e o direito à saúde. São Paulo, Hucitec, 1995.

. Poderes republicanos e a defesa do direito à saúde: evolução da proteção do direito à saúde nas Constituições do Brasil. In: BRASIL. Ministério da Saúde. Direito Sanitário em Perspectiva. Brasília: Fundação Oswaldo Cruz, 2013. v. 2.

. Uma nova disciplina: o direito sanitário. Revista de Saúde Pública, São Paulo, v. 22, n. 4, p. 327-334, ago. 1988 .

. A vigilância sanitária no contexto constitucional e legal brasileiro. Belo Horizonte: Coopmed, 2001.

FERREIRA, Fátima de Paula; CASTRO, Larissa de Paula Gonzaga. O direito à saúde e a globalização. Revista Anhanguera, v. 11, n. 01, jan./dez. 2010, p. 61-87. Disponível em: $<$ http://www.anhanguera.edu.br/home/index.php?option=com_docman\&Itemid=373 >. Acesso em: 10 jul. 2013.

FOUCAULT, Michel. Microfísica do poder. 5. ed. Rio de Janeiro: Edições Graal, 1985.

GELIS FILHO, Antônio. Globalização, serviços de saúde e Direito Internacional. Revista de Direito Sanitário, São Paulo, v. 2, n. 3, nov. 2001.

GODINHO, Fabiana de Oliveira. A proteção internacional dos direitos humanos. Belo Horizonte: Del Rey, 2006.

GOMES, Carolina B.; CASTRO, Larissa de P. Gonzaga e. O novo Regulamento Sanitário Internacional. Revista de Direito Sanitário, São Paulo, v. 13, n. 2, p. 137-155, jul./out. 2012.

KOLLING, Gabriele; MASSAÚ, Guilherme Camargo. Cidadania supranacional e o direito à saúde. Ciências Sociais Aplicadas em Revista, Marechal Cândido Rondon, v. 10, n. 19, 2. sem. 2010. 
LASMAR, Jorge Mascarenhas; CASARÕES, Guilherme Stolle Paixão e. A Organização das Nações Unidas. Belo Horizonte: Del Rey, 2006.

LIMA, Abili Lázaro Castro de. Globalização econômica, política e direito: análise das mazelas causadas no plano político-jurídico. Porto Alegre: Sérgio Antônio Fabris Editor, 2002.

LUCCHESE, Geraldo. A internacionalização da regulamentação sanitária. Ciência \& Saúde Coletiva, Rio de Janeiro, v. 8, n. 2, p. 551, 2003. Disponível em: <http://www.scielo.br/scielo. php?script=sci_arttext\&pid=S1413-81232003000200016>. Acesso em: 05 ago. 2013.

MARÉS, Carlos Frederico. A universalidade parcial dos direitos humanos (Trabalho preparado especialmente para o Taller ILSA Región Andina "Los derechos indígenas em ela actual contexto latinoamericano". Quito, 27/29 de outubro de 1994). Curitiba, 25 out. 1994.

MíNGUEZ GONZALO, Miguel. El nuevo reglamento sanitário internacional. Revista Española de Salud Pública, Madrid, n. 03, p. 239-246, maio/jun. 2007. Disponível em: <http:// scielo.isciii.es/pdf/resp/v81n3/editorial.pdf>. Acesso em: 01 ago. 2013.

OLIVEIRA, Euclides Benedito. Direito à saúde: garantia e proteção pelo poder judiciário. Revista de Direito Sanitário, São Paulo, v. 2, n. 3, p. 36-58, nov. 2001.

PEREIRA, Bruno Yepes. Curso de direito internacional público. 2. ed. São Paulo: Saraiva, 2007.

PORTAL da Saúde. Disponível em: <http://portal.saude.gov.br/portal/saude/profissional/ area.cfm?id_area=1111>. Acesso em: 05 de ago. 2013.

PORTAL da Saúde. Subgrupo de Trabalho n. 11. Disponível em: <http://portal.saude.gov. br/portal/saude/profissional/visualizar_texto.cfm?idtxt=27171>. Acesso em: 25 jul. 2013.

RAMOS, André de Carvalho. Teoria geral dos direitos humanos na ordem internacional. São Paulo: Renovar, 2005.

REZENDE, Ana Lúcia Magela de. Saúde: dialética do pensar e do fazer. 2. ed. São Paulo: Cortez, 1989.

ROSEN, George. Uma história da saúde pública. 2. ed. São Paulo: Hucitec, 1994.

ROSENBERG, Félix J. Mecanismos legais de controle da segurança do medicamento. Revista de Direito Sanitário. v. 2, n. 1, mar. 2001.

SANTOS, Boaventura de Sousa. La globalización del derecho: los nuevos caminhos de la regulación y la emancipación. Bogotá: ILSA, 1998.

SARLET, Ingo Wolfgang. A eficácia dos direitos fundamentais: uma teoria geral dos direitos fundamentais na perspectiva constitucional. 10. ed. rev., atual. e ampl. Porto Alegre, RS: Livraria do Advogado, 2011.

SCHWARTZ, Germano. Direito à saúde: efetivação em uma perspectiva sistêmica. Porto Alegre: Livraria do Advogado, 2001. 
SEPULCRI, Nayara Tataren. Propriedade intelectual e desenvolvimento: uma análise sobre a problemática das patentes farmacêuticas no Mercosul. p. 35-68. In: FRIEDRICH, Tatyana Scheila; BACELLAR FILHO, Romeu Felipe. Aspectos jurídicos da aproximação dos países com vistas ao desenvolvimento. Curitiba: Íthala, 2010.

SILVA, José Afonso da. Curso de direito constitucional positivo. 33. ed. rev. e atual. São Paulo: Saraiva, 2010.

SOARES, Guido F. S. Aspectos internacionais da segurança sanitária num mundo globalizado: o regulamento sanitário internacional e a organização mundial do comércio. In: SEMINÁRIO INTERNACIONAL DE DIREITO SANITÁRIO, 5., 1999, São Paulo, Anais... São Paulo: Universidade de São Paulo, 1999, p. 151-175.

TERUCHKIN, Sônia Unikowsky. A proteção dos consumidores no Mercosul: algumas considerações. Indicadores Econômicos FEE, v. 25, n. 4, p. 278-293, 1998.

TORRONTEGUY, Marco Aurélio Dantas. O direito humano à saúde no direito internacional: efetivação por meio da cooperação sanitária. Tese (Doutorado). 2010. Disponível em: $<$ http://www. teses.usp.br/teses/disponiveis/2/2140/tde-14032011-154326/fr.php>. Acesso em: 01 ago. 2013.

TRINDADE, Antônio Augusto Cançado. Princípios do direito internacional contemporâneo. Brasília: UnB, 1981.

. A proteção internacional dos direitos humanos: fundamentos jurídicos e instrumentos básicos. São Paulo: Saraiva, 1991.

VENTURA, Deisy de Freitas Lima. Direito internacional sanitário. In: ARANHA, Márcio Iorio (Coord.). Direito sanitário e saúde pública. Coletânea de Textos. Ministério da Saúde. Secretaria de Gestão do Trabalho e da Educação na Família. Departamento de Gestão da Educação da Saúde. Brasília: Ministério da Saúde, 2003.

VILLEY, Michel. O direito e os direitos humanos. Trad. de Maria Ermantina de Almeida Prado Galvão. São Paulo: Martins Fontes, 2007.

WESTPHAL, Marcia Faria. Promoção da saúde e a qualidade de vida. In: ROCHA, Aristides Almeida; CESAR, Chester Luiz Galvão. Saúde Pública: bases conceituais. São Paulo: Atheneu, 2008.

Carla Liliane Waldow Esquivel - Doutoranda em Direito pela Universidade Federal do Paraná. Professora de Direito Penal na Universidade Estadual do Oeste do Paraná. Membro do Núcleo de Pesquisa em Direito Público do Mercosul da Universidade Federal do Paraná. Marechal Cândido Rondon/PR, Brasil.E-mail: carlawaldow@hotmail.com

Tatyana Scheila Friedrich - Doutora em Direito. Professora de Direito Internacional na Universidade Federal do Paraná. Líder do Núcleo de Pesquisa em Direito Público do Mercosul da Universidade Federal do Paraná.Curitiba/PR, Brasil.E-mail: tatyanafriedrich@yahoo.com. 